\title{
Analisis Ketelitian Orthorektifikasi Citra Pleiades dan SPOT6 Untuk Pembuatan Peta Dasar RDTR Wilayah Pesisir (Studi Kasus: Kecamatan Jenu, Tuban)
}

\author{
Friska Melia Ode Binta dan Bangun Muljo Sukojo \\ Departemen Teknik Geomatika, Fakultas Teknik Sipil dan Perencanaan, Institut Teknologi \\ Sepuluh Nopember (ITS) \\ e-mail: bangunms@gmail.com
}

\begin{abstract}
Abstrak-Wilayah pesisir Kabupaten Tuban dalam berbagai rencana tata ruang direncanakan menjadi salah satu pusat pertumbuhan ekonomi di Jawa Timur. Rencana tersebut memerlukan peta Rencana Detail Tata Ruang (RDTR), khususnya Wilayah Pesisir dengan ketelitian tinggi. Namun peta RDTR yang digunakan saat ini masih belum memiliki ketelitian tinggi. Oleh karena itu, tujuan dalam penelitian ini adalah melakukan analisis ketelitian orthorektifikasi citra satelit resolusi tinggi, sehingga dapat digunakan untuk pembuatan peta dasar RDTR. Dalam penelitian ini dilakukan proses orthorektifikasi menggunakan data citra satelit Pleiades 1A dan SPOT6 dengan metode Rational Polynomial Coefficient (RPC). Sebagai data penunjang yaitu data Titik Kontrol Tanah (GCP) sebanyak 11 titik dan titik Uji Akurasi (ICP) sebanyak 12 titik dan data DEM Astrium Terra SAR-X untuk koreksi ketinggian citra satelit, sehingga menjadi citra tegak. Berdasarkan pengolahan dan analisis data didapatkan nilai ketelitian horizontal citra Tegak Pleiades 1A sebesar 0,3 meter dan citra Tegak SPOT6 sebesar 1,8 meter. Berdasarkan nilai ketelitian horizontal tersebut bahwa citra satelit Pleiades 1A dan SPOT6 memenuhi standar ketelitian horizontal peta dasar skala 1:5000 dan 1:10.000 sesuai dengan Perka BIG No 15 tahun 2014. Selain itu, dalam penelitian ini juga dilakukan perhitugan konsentrasi TSS citra satelit Pleiades 1A dan SPOT6 menggunakan algoritma Laili tahun 2015. Dari hasil pengolahan citra dan data grount truth dapat dikatakan bahwa konsentrasi TSS tergolong rendah $(<100 \mathrm{mg} / \mathrm{l})$ sesuai Permen LH Nomor 01 tahun 2010. Dengan demikian dapat dikatakan bahwa perairan laut di Kecamatan Jenu tergolong bersih dan hal tersebut tidak mempengaruhi perubahan garis pantai. Hasil uji korelasi TSS citra Pleiades 1A dan SPOT6 dengan data ground truth tergolong sangat kuat sedangkan data citra Pleiades 1A dan SPOT6 dengan data foto udara memiliki koefisien korelasi yang tergolong rendah dan sangat rendah.
\end{abstract}

Kata kunci-Orthorektifikasi , Pleiades 1A, SPOT6, TSS, Wilayah Pesisir.

\section{PENDAHULUAN}

$\mathrm{T}$ UBAN merupakan salah satu kabupaten yang berada di wilayah pesisir utara Pulau Jawa dengan garis pantai sepanjang $65 \mathrm{~km}$ dan luas lautan 22,608 km² yang terbentang dari arah timur Kecamatan Palang sampai arah barat Kecamatan Bulu Bancar [1]. Di sepanjang pesisir Kabupaten Tuban terdapat banyak infrastruktur dan pusat-pusat kegiatan, antara lain jalan arteri primer Pantura yang menghubungkan Jawa Timur - Jawa Barat, pelabuhan, pergudangan, industri, permukiman, dan pariwisata. Kawasan pesisir tersebut direncanakan sebagai kawasan industri Terpadu Jawa Timur dengan adanya rencana pembangunan pelabuhan, pengembangan kota perikanan dan pelabuahan, serta pembangunan kawasan minapolitan [2].

Sebagai pusat kegiatan dan ekonomi, wilayah pesisir Kabupaten Tuban harus memiliki perencanaan pemanfaatan ruang wilayah yang baik dan sesuai dengan peraturan perundang-undangan yang berlaku. Untuk itu, agar tidak terjadi kerancuan yang dapat mengakibatkan kerusakan lingkungan dan ekosistem, maka diperlukan peta detail tata ruang (RDTR) khususnya wilayah pesisir yang memiliki ketelitian tinggi. Namun dewasa ini, banyak peta RDTR yang belum memiliki ketelitian tinggi sesuai dengan aturan dari Kepala BIG [3].

Dalam pembuatan peta RDTR dibutuhkan citra satelit resolusi tinggi yang memiliki cakupan yang luas serta dapat menggambarkan kenampakan fisik sesuai dengan kenampakan di lapangan, sehingga memberikan informasi yang akurat. Seperti yang diketahui bahwa dalam proses perekaman citra satelit terdapat beberapa faktor kesalahan yang diakibatkan oleh pergeseran dan kemiringan serta variasi topografi yang membuat informasi koordinat dan ketinggian citra tidak sesuai dengan keadaan sesungguhnya. Sehingga perlu dilakukan proses orthorektifikasi yang bertujuan untuk mengurangi berbagai distorsi yang disebabkan oleh kemiringan kamera/sensor dan pergeseran relief [4].

Selain proses orthorektifikasi juga perlu dilakukan analisis ketelitian orthorektifikasi citra Pleiades dan SPOT6 terhadap kondisi lapangan. Sehingga diperlukan penelitian untuk mengetahui ketelitian orthorektifikasi citra Pleiades dan SPOT6 untuk Kabupaten Tuban khususnya Kecamatan Jenu yang memiliki pembangunan cukup pesat [2]. Oleh karena itu, pada studi ini penulis akan melakukan analisis ketelitian orthorektifikasi citra Pleiades dan SPOT6 untuk memberi rekomendasi pembuatan peta dasar RDTR wilayah pesisir 1:5000 dan 1:10.000 yang mengacu pada Pedoman Teknis Ketelitian Peta Dasar 2014 [3].

\section{METODOLOGI PENELITIAN}

\section{A. Lokasi Penelitian}

Lokasi penelitian dalam penelitian ini yaitu di Kecamatan Jenu, tepatnya $10 \mathrm{~km}$ arah barat kota Tuban dengan luas wilayah $81,62 \mathrm{~km}^{2}$. Secara geografis berada di $6^{\circ} 49^{\prime} 16^{\prime \prime} \mathrm{LS}$

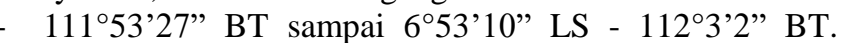
Dengan batas administrasi sebelah utara berbatasan dengan Laut Jawa, sebelah timur berbatasan dengan Kecamatan 
Tuban, sebalah selatan berbatasan Kecamatan Merakurak, dan sebelah barat berbatasan dengan Kecamatan Tambakboyo.

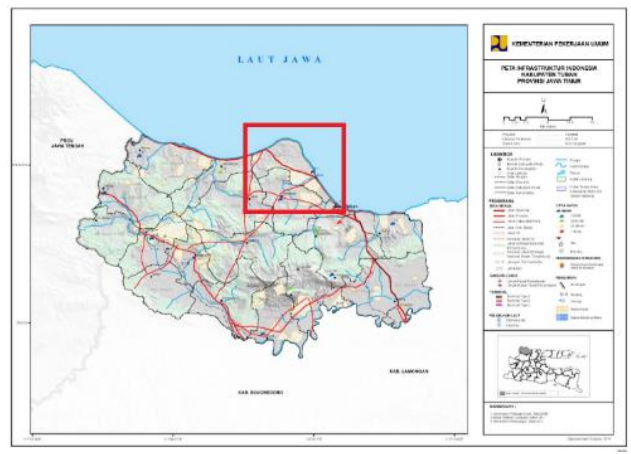

Gambar 1. Lokasi Penelitian

\section{B. Data dan Peralatan}

\section{1) Data}

Adapun data yang digunakan dalam penelitian ini yaitu:

a. Citra satelit Pleiades 1A 2015

b. Citra satelit SPOT6 2015

c. DEM Astrium Terra SAR X

d. Peta Rupa Bumi Indonesia (RBI) 1:25000

e. Data Citra Foto

f. Koordinat titik GCP dan ICP dari hasil pengukuran GPS.

2) Peralatan

Peralatan yang digunakan dalam penelitian ini yaitu:

1. Perangkat Keras

a. GPS Geodetik

b. Statif dan tribrach

c. Pita ukur

d. Kamera Phantom 3 advance

e. Laptop

f. Alat tulis dan form survei

2. Perangkat Lunak

a. Microsoft Office

b. Perangkat lunak pengolah citra satelit

c. Perangkat lunak pengolah orthorektifikasi

d. Perangkat lunak pengolah perhitungan data

e. Perangkat lunak pengolah data GPS

\section{Diagram Alir Pengolahan Data}

Tahapan pengolahan data pada penelitian ini adalah sebagai berikut:

1. Data yang digunakan dalam penelitian ini yaitu citra satelit Pleiades 1A dan SPOT6, DEM Astrium Terra SAR-X, data titik koordinat GCP dan ICP, peta RBI 1:25.000 data foto udara wilayah pesisir serta data uji sampel TSS.

2. Pansharpening dilakukan untuk mendapatkan resolusi spasial yang tinggi dengan menggabungan kanal multispketral dan pankromatrik.

3. Cropping area menggunakan peta RBI 1:25000 sesuai batas administrasi daerah studi kasus yaitu Kecamatan Jenu, Tuban.

4. Pembuatan desain jaring dilakuakan berdasarkan titiktitik yang telah didapatkan dengan menghubungkan titik menjadi jaring dan selanjutnya dihitung nilai SoF $\leq 1$.

5. Interpolasi GCP untuk mencari koordinat pendekatan yang nantinya akan digunakan untuk pengukuran lapangan. Data GCP hasil pengukuran lapangan selanjtnya akan digunakan dalam proses orthorektifikasi yang sebelumnya telas diolah menggunakan perangkat lunak pengeolah GPS.

6. Proses orthorektifikasi menggunakan data DEM Astrium dan koordinat GCP yang didapatkan dari hasil pengukuran lapangan menggunakan GPS. Metode yang digunakan orthorektifikasi yaitu metode Rational Polynomial Coefficient (RPC) dengan nilai RMSE $\leq 1,5$ pixel.

7. Hasil orthorektifikasi berupa citra tegak Pleiades $1 \mathrm{~A}$ dan SPOT6.

8. Proses interpolasi ICP digunakan untuk mengetahui koordinat pendekatan yang akan digunakan pada saat pengukuran lapangan. Setelah pengukuran ICP lapangan didapatkan koordinat ICP lapangan yang sebelumnya diolah menggunakan perangkat lunak pengolah data GPS dan nantinya akan digunakan untuk proses uji ketelitian.

9. Proses uji ketelitian geometrik menggunakan koordinat titik ICP yang telah dilakukan dilapangan, dimana uji ketelitian mengacu pada ketentuan Peraturan Kepala BIG Tentang Ketelitian Peta Dasar beserta Modul Validasi Peta Rencana Tata Ruang [5].

10. Perhitungan TSS citra satelit menggunakan algoritma Laili, 2015[6].

$$
\mathrm{TSS}=31,42 * \frac{\log \rho R E D}{\log \rho N I R}-12,719(\mathrm{mg} / \mathrm{L})
$$

Sebagai data pendukung analisis mengenai perubahan garis pantai, kemudian dilakukan validasi data TSS lapangan hasil pengambilan foto udara wilayah pesisir dan uji sampel TSS. Adapun pengambilan sampel TSS dilakukan seperti dibawah ini:

a.Siapkan botol yang telah ditutup dengan lakban, hal ini dilakukan untuk mengurangi paparan sinar matahari secara langsung.

b. Botol diberi pemberat agar dapat digunakan pada kedalaman tertentu.

c.Ambil sampel air (TSS) pada lokasi yang telah ditentukan.

d. Beri label pada botol, agar tidak tertukar dengan lokasi yang lain.

e.Kemudian dilakukan uji sampel di laboratorium Departemen Lingkungan Hidup (DLH) Tuban untuk mendapatkan nilai konsentrasi TSS.

11. Hasil perhitungan TSS citra dan validasi data TSS lapangan dilakukan korelasi untui mengetahui hubungan antara kedua data. Data konsetrasi TSS tersebut digunakan untuk mendukung analisis mengenai kemungkinan adanya perubahan garis pantai.

12. Pada proses analisis terdapat dua data yang dilakukan analisis yaitu hasil uji ketelitian horizontal dan hasil korelasi data TSS citra dan lapangan. Dimana hasil konsetrasi TSS digunakan sebagai data pendukung analisis mengenai perubahan garis pantai.

13. Peta definitif yang dimaksud berupa peta rekomendasi untuk pembuatan peta dasar RDTR wilayah pesisir Kecamatan Jenu, Tuban skala 1:5000 untuk citra Pleiades 1A dan 1:10.000 untuk citra SPOT6. 


\section{HASIL DAN ANALISA}

\section{B. Desain dan Kekuatan Jaring}

Penentuan posisi dari titik kontrol tanah (GCP) untuk keperluan koreksi gemetrik diperlukan adanya perencanaan dan perhitungan kekuatan jaring/ Strength of Figure (SoF). Semakin kecil bilangan faktor kekuatan jaring, maka akan semakin baik konfigurasi jaring yang bersangkutan, dan sebaliknya [6]. Bentuk desain jaring yang telah dibentuk dapat dilihat pada Gambar 2.

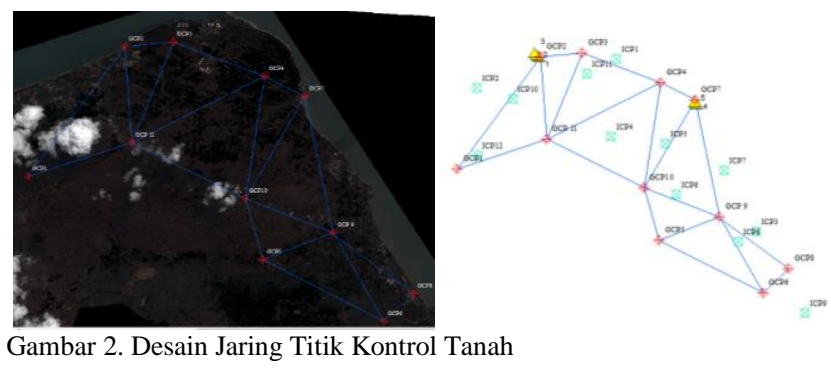

Untuk melihat kekuatan dari jaring yang dibentuk, maka dilakukan perhitungan kekuatan jaring menggunakan rumus sebagai berikut:

$$
\begin{array}{ll}
\text { Jumlah baseline } & : 31 \\
\text { Jumlah titik } & : 11 \\
\text { N_ukuran } & : \text { Ebaseline x } 3=93 \\
\text { N_parameter } & : \text { Etitik x } 3=33 \\
\text { U } & :(\text { N_ukuran })-(\text { N_parameter })=60 \\
\text { Sof }=\frac{\left[\text { Trace }\left(A^{\mathrm{T}} A\right)^{-1}\right]}{U}=0,216
\end{array}
$$

Dari hasil perhitungan tersebut, maka dapat dikatakan bahwa desain jaring yang dibuat telah memenuhi toleransi dan dianggap kuat [6].

\section{Koordinat Titik Kontrol Tanah (GCP)}

Pengukuran titik kontrol tanah pada penelitian ini menggunakan GCP Geodetik dengan metode diferensial statik menggunkan 3 GPS dengan durasi pengukuran \pm 60 menit. Hasil pengukuran diolah menggunakan perangkat lunak pengolah GPS meliputi proses post processing (pengolahan baseline) dan network adjustment (perataan jaring).

Koordinat GCP ini diikatkan dengan koordinat CORS ITSS dan SRGI di wilayah Tuban, dengan selisih koordinat SRGI pengukuran dan SRGI BIG sebagai beriku:

\begin{tabular}{|c|c|c|}
\hline \multirow[t]{2}{*}{ Point ID } & \multicolumn{2}{|c|}{ Koordinat GCP } \\
\hline & $\mathrm{X}(\mathrm{m})$ & $\mathrm{Y}(\mathrm{m})$ \\
\hline GCP 01 & 600491,450 & 9246507,632 \\
\hline GCP 02 & 603117,845 & 9251281,283 \\
\hline GCP 03 & 604623,091 & 9251459,875 \\
\hline GCP 04 & 607571,479 & 9250219,753 \\
\hline GCP 05 & 608088,481 & 9243562,887 \\
\hline GCP 06 & 612050,928 & 9241354,470 \\
\hline GCP 07 & 608909,184 & 9249528,496 \\
\hline GCP 08 & 612881,915 & 9242403,060 \\
\hline GCP 09 & 610201,187 & 9244564,668 \\
\hline GCP 10 & 607356,837 & 9245760,250 \\
\hline GCP 11 & 603632,382 & 9247795,181 \\
\hline
\end{tabular}

$$
\begin{aligned}
& \mathrm{dx}=-4,306 \text { meter } \\
& \mathrm{dy}=0,391 \text { meter }
\end{aligned}
$$

Sehingga didapatkan koordinat GCP sebagai berikut:

$$
\text { Tabel } 1 .
$$

Koordinat Titik Kontrol Tanah di Ikatkan dengan SRGI BIG

\section{Orthorektifikasi}

Pada penelitian ini dilakukan proses orthorektifikasi menggunakan metode Rational Polynomial Coefficeint (RPC). Pada proses orthorektifiaksi menggunakan data 11 koordinat titik GCP dan DEM Astrium Terra SAR-X sebagai koreksi ketinggian yang diolah dengan software pengolah orthorektifikasi sehingga didapatlan nilai RMSE.

Dari hasil pengolahan orthorektifikasi didapatkan nilai RMSE citra Pleiades 1A sebesar 0,108 meter dengan rincian pada Tabel 2.

Tabel 2.

Nalai RMSE GCP Citra Pleiades IA

\begin{tabular}{cccc}
\hline \hline Point ID & \multicolumn{2}{c}{ Koordinat GCP Pleiades 1A } & RMSE \\
& $\mathrm{X}(\mathrm{m})$ & $\mathrm{Y}(\mathrm{m})$ & $(\mathrm{m})$ \\
\hline GCP 01 & 600491,450 & 9246507,632 & 0,085 \\
GCP 02 & 603117,845 & 9251281,283 & 0,045 \\
GCP 03 & 604623,091 & 9251459,875 & 0,01 \\
GCP 04 & 607571,479 & 9250219,753 & 0,04 \\
GCP 05 & 608088,481 & 9243562,887 & 0,18 \\
GCP 06 & 612050,928 & 9241354,470 & 0,21 \\
GCP 07 & 608909,184 & 9249528,496 & 0,11 \\
GCP 08 & 612881,915 & 9242403,060 & 0,16 \\
GCP 09 & 610201,187 & 9244564,668 & 0,13 \\
GCP 10 & 607356,837 & 9245760,250 & 0,115 \\
GCP 11 & 603632,382 & 9247795,181 & 0,15 \\
& RMSE & 0,108 \\
\hline \hline
\end{tabular}

Sedangkan nilai RMSE citra SPOT6 sebesar 0,642 meter dengan rincian pada Tabel 3.

Tabel 3.

Nilai RMSE GCP Citra SPOT6

\begin{tabular}{cccc}
\hline \hline Point ID & \multicolumn{2}{c}{ Koordinat GCP SPOT6 } & RMSE $(\mathrm{m})$ \\
& $\mathrm{X}(\mathrm{m})$ & $\mathrm{Y}(\mathrm{m})$ & \\
\hline GCP 01 & 600491,450 & 9246507,632 & 0,31 \\
GCP 02 & 603117,845 & 9251281,283 & 0,35 \\
GCP 03 & 604623,091 & 9251459,875 & 0,39 \\
GCP 04 & 607571,479 & 9250219,753 & 0,35 \\
GCP 05 & 608088,481 & 9243562,887 & 0,99 \\
GCP 06 & 612050,928 & 9241354,470 & 0,58 \\
GCP 07 & 608909,184 & 9249528,496 & 1,25 \\
GCP 08 & 612881,915 & 9242403,060 & 0,35 \\
GCP 09 & 610201,187 & 9244564,668 & 0,33 \\
GCP 10 & 607356,837 & 9245760,250 & 0,37 \\
GCP 11 & 603632,382 & 9247795,181 & 1,75 \\
\multicolumn{4}{c}{ RMSE } \\
\hline \hline
\end{tabular}

Dimana nilai RMSE kedua citra tersebut telah memenuhi toleransi yang ditetapkan oleh Peraturan Kepala BIG, 2014[3].

\section{E. Uji Ketelitian}

Dalam penelitian ini dilakukan uji ketelitian menggunakan titik ICP yang berjumlah 12 titik sesuai dengan persyaratan Modul Validasi Peta Rencana Tata Ruang [5]. Sebaran titik ICP dapat dilihat pada Gambar 3.

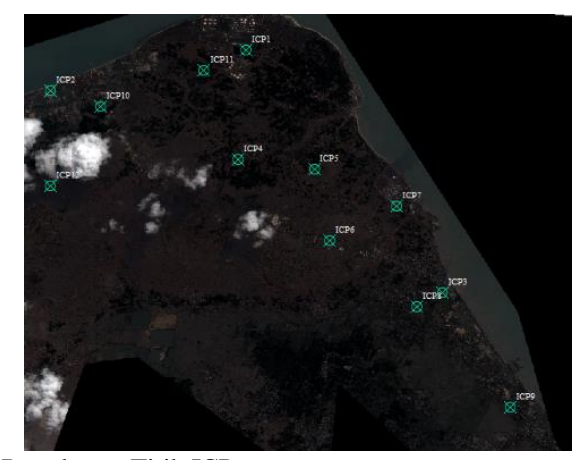

Gambar 3. Persebaran Titik ICP 
Pengukuran titik ICP menggunakan GPS Geodetik metode rapid static dengan durasi \pm 15 menit, Hasil pengukuran diolah menggunakan perangkat lunak pengolah GPS meliputi proses post processing (pengolahan baseline) dan network adjustment (perataan jaring).

Koordinat ICP ini diikatkan dengan koordinat CORS ITSS dan SRGI di wilayah Tuban, dengan selisih koordinat SRGI pengukuran dan SRGI BIG sebagai beriku:

$$
\begin{aligned}
& \mathrm{dx}=-4,306 \text { meter } \\
& \mathrm{dy}=0,391 \text { meter }
\end{aligned}
$$

Sehingga didapatkan koordinat ICP sebagai berikut: Tabel 4.

\begin{tabular}{ccc} 
Tabel Koordinat Titik ICP di Ikatkan dengan SRGI BIG \\
\hline \multirow{2}{*}{ Point } & \multicolumn{2}{c}{ Koordinat ICP } \\
ID & $\mathrm{X}(\mathrm{m})$ & $\mathrm{Y}(\mathrm{m})$ \\
\hline ICP 01 & 605904,661 & 9251229,177 \\
ICP 02 & 600895,765 & 9249945,277 \\
ICP 03 & 611581,194 & 9243931,582 \\
ICP 04 & 605975,440 & 9247901,147 \\
ICP 05 & 607964,143 & 9247642,874 \\
ICP 06 & 608545,470 & 9245485,737 \\
ICP 07 & 610194,207 & 9246532,696 \\
ICP 08 & 610939,411 & 9243523,843 \\
ICP 09 & 613761,734 & 9240444,200 \\
ICP 10 & 602254,210 & 9249478,350 \\
ICP 11 & 604842,409 & 9250578,954 \\
ICP 12 & 601166,593 & 9247059,155 \\
\hline
\end{tabular}

Untuk mengetahui ketelitian hasil orthorektifikasi dilakukan perhitungan uji ketelitian horizontal menggunakan titk ICP. Dan dipatkan nilai RMSE ICP citra Pleiades 1A sebesar 0,259 meter, dengan rincian pada Tabel 5 .

Tabel 5.

\begin{tabular}{|c|c|c|c|}
\hline \multirow[t]{2}{*}{ Point ID } & \multicolumn{2}{|c|}{ Koordinat ICP Pleiades 1A } & \multirow[t]{2}{*}{ RMSE (m) } \\
\hline & $\mathrm{X}(\mathrm{m})$ & $\mathrm{Y}(\mathrm{m})$ & \\
\hline ICP 01 & 605904,661 & 9251229,177 & 0,04 \\
\hline ICP 02 & 600895,765 & 9249945,277 & 0,31 \\
\hline ICP 03 & 611581,194 & 9243931,582 & 0,24 \\
\hline ICP 04 & 605975,440 & 9247901,147 & 0,33 \\
\hline ICP 05 & 607964,143 & 9247642,874 & 0,22 \\
\hline ICP 06 & 608545,470 & 9245485,737 & 0,2 \\
\hline ICP 07 & 610194,207 & 9246532,696 & 0,17 \\
\hline ICP 08 & 610939,411 & 9243523,843 & 0,12 \\
\hline ICP 09 & 613761,734 & 9240444,200 & 0,21 \\
\hline ICP 10 & 602254,210 & 9249478,350 & 0,11 \\
\hline ICP 11 & 604842,409 & 9250578,954 & 0,05 \\
\hline \multirow[t]{2}{*}{ ICP 12} & 601166,593 & 9247059,155 & 0,03 \\
\hline & RMSE & & 0,259 \\
\hline
\end{tabular}

Nilai RMSE ICP Citra Pleiades IA

Sedangkan nilai RMSE ICP citra SPOT6 sebesar 1,195 meter, dengan rincian pada Tabel 5.

Tabel 6.

Nilai RMSE ICP Citra SPOT6

\begin{tabular}{cccc}
\hline \hline Point ID & \multicolumn{2}{c}{ Koordinat ICP SPOT6 } & RMSE \\
& $\mathrm{X}(\mathrm{m})$ & $\mathrm{Y}(\mathrm{m})$ & $(\mathrm{m})$ \\
\hline ICP 01 & 605904,661 & 9251229,177 & 1,18 \\
ICP 02 & 600895,765 & 9249945,277 & 2,8 \\
ICP 03 & 611581,194 & 9243931,582 & 2,4 \\
ICP 04 & 605975,440 & 9247901,147 & 2,51 \\
ICP 05 & 607964,143 & 9247642,874 & 1,30 \\
ICP 06 & 608545,470 & 9245485,737 & 0,22 \\
ICP 07 & 610194,207 & 9246532,696 & 0,30 \\
ICP 08 & 610939,411 & 9243523,843 & 1,06 \\
ICP 09 & 613761,734 & 9240444,200 & 0,36 \\
ICP 10 & 602254,210 & 9249478,350 & 0,31 \\
ICP 11 & 604842,409 & 9250578,954 & 0,38 \\
ICP 12 & 601166,593 & 9247059,155 & 1,41 \\
& RMSE & 1,195 \\
\hline \hline
\end{tabular}

Dari pengolahan data didapatkan nilai RMSE ICP 0,259 meter untuk citra Tegak Pleiades 1A dan 1,195 meter untuk citra Tegak SPOT6. Berdasarkan dari hasil perhitungan uji ketelitian menggunakan titik ICP sesuai dengan aturan Perka BIG 2014 [3], didapatkan ketelitian horizontal citra Pleiades 1A 0,2 meter dan 1,8 meter untuk citra tegak SPOT6.

\section{F. Analisis Ketelitian}

Dari hasil uji ketelitian horizontal citra Tegak Pleiades 1A dan SPOT6 dapat dilihat pada Tabel 7. Tabel 7 .

Nilai Ketelitian Citra Tegak Pleiades 1A dan SPOT6

\begin{tabular}{lcccccc}
\hline \hline \multicolumn{1}{c}{ Citra Tegak } & \multicolumn{2}{c}{ Kelas 1 } & \multicolumn{3}{c}{ Kelas 2 } & \multicolumn{2}{c}{ Kelas 3 } \\
& $\mathrm{H}(\mathrm{m})$ & $\mathrm{V}(\mathrm{m})$ & $\mathrm{H}(\mathrm{m})$ & $\mathrm{V}(\mathrm{m})$ & $\mathrm{H}(\mathrm{m})$ & $\mathrm{V}(\mathrm{m})$ \\
\hline Pleiades 1A & 0,3 & - & - & - & - & - \\
SPOT6 & - & - & - & - & 1,8 & - \\
\hline \hline
\end{tabular}

Sesuai dengan Peraturan Kepala Badan Informasi Geospasial Nomor 15 tahun 2014 tentang pedoman teknis Peta Dasar[3], dilakukan perhitungan ketelitian horizontal citra Tegak Pleiades 1A dan SPOT6. Dari hasil perhitungan ketelitian horizontal tersebut didapatkan nilai citra Tegak Pleiades $1 \mathrm{~A}$ sebesar $0,3 \mathrm{~m}$ yang artinya hasil orthorektifikasi citra Tegak Pleiades 1A memenuhi syarat dan dapat digunakan untuk pembuatan peta dasar RDTR skala 1: 2.500 kelas 1 dengan syarat ketelitian horizontal 0,5 meter. Sedangkan citra Tegak SPOT6 didapatkan ketelitian horizontal sebesar 1,8 m yang artinya telah memenuhi syarat untuk digunakan pembuatan peta dasar RDTR skala 1: 5.000 kelas 3 dengan syarat ketelitian horizontal 2,5 meter.

\section{G. Perhitungan Total Suspended Solid (TSS)}

Dalam penelitian ini dilakukan perhitungan TSS citra satelit Pleiades 1A dan SPOT6 menggunakan algoritma dari Laili tahun 2015 [7]. Data TSS tersebut digunakan sebagai pendukung analisis tentang kemungkinan adanya perubahan garis pantai. Dari perhitungan tersebut didapatkan konsentrasi TSS seperti rincian pada Tabel 8.

Tabel 8.

\begin{tabular}{|c|c|c|c|}
\hline $\begin{array}{l}\text { Point } \\
\text { ID }\end{array}$ & Definisi & $\begin{array}{c}\text { TSS Citra } \\
\text { Pleiades 1A } \\
(\mathrm{mg} / \mathrm{L})\end{array}$ & $\begin{array}{c}\text { TSS Citra } \\
\text { SPOT6 } \\
(\mathrm{mg} / \mathrm{L})\end{array}$ \\
\hline UJI 01 & $0 \mathrm{~m}$ dari Pesisir & 17,109 & 12,701 \\
\hline UJI 02 & $\begin{array}{l}100 \mathrm{~m} \text { dari } \\
\text { Pesisir }\end{array}$ & 24,066 & 26,121 \\
\hline UJI 03 & $\begin{array}{l}200 \mathrm{~m} \text { dari } \\
\text { Pesisir }\end{array}$ & 20,729 & 22,123 \\
\hline UJI 04 & $0 \mathrm{~m}$ dari Pesisir & 24,737 & 21,3 \\
\hline UJI 05 & $\begin{array}{l}100 \mathrm{~m} \text { dari } \\
\text { Pesisir }\end{array}$ & 44,366 & 50,701 \\
\hline
\end{tabular}

Nilai Konsentrasi TSS Citra Pleiades 1A dan SPOT6

Dari penelitian diatas kemudiandisajikan dalam bentuk grafik seperti pada Gambar 4.

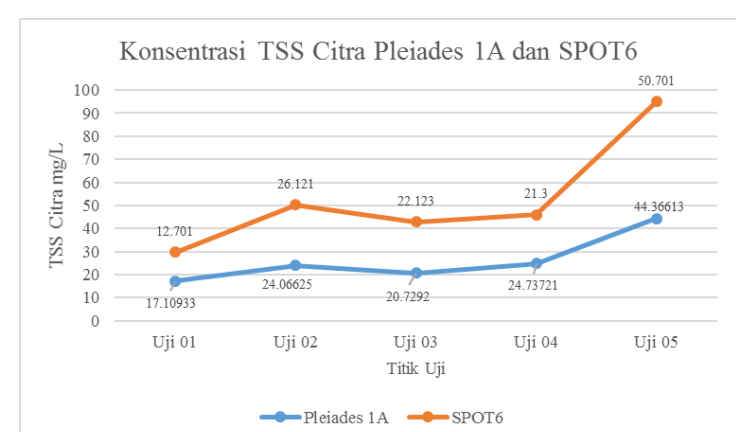

Gambar 4. Grafik Nilai Konsentrasi TSS Citra Pleiades 1A dan SPOT6

Dari Gambar 7 dapat dilihat bahwa pada titik uji 05 yang terletak \pm 100 meter dari pantai memiliki konsentrasi TSS 
tertinggi, hal tersebut disebabkan lokasi titik uji 05 berada tidak jauh dari pabrik dan adanya aktifitas transportasi laut. Sedangkan konsentrasi TSS terendah yaitu pada titik uji 01 yang berada dipinggir pantai, hal tersebut disebabkan lokasi uji titik 01 jauh dengan area permukiman dan muara sungai.

\section{H. Uji Korelasi TSS Citra dan Ground Truth}

Pada penelitian ini juga dilakukan uji korelasi antara nilai TSS citra dan lapangan (ground truth). Data citra yang digunakan yaitu citra satelit Pleiades 1A 21 Agustus 2015, SPOT6 Juni 2015 dan data lapangan 14 April 2017 dengan rincian seperti pada Tabel 9.

Tabel 9.

Perbandingan Nilai Konsentrasi TSS Citra Pleiades 1A, SPOT6 dan Lapangan

\begin{tabular}{cccc}
\multicolumn{3}{c}{ Lapangan } & \\
\hline \hline $\begin{array}{c}\text { Point } \\
\text { ID }\end{array}$ & $\begin{array}{c}\text { Nilai TSS Citra } \\
\text { Pleiades 1A mg/L }\end{array}$ & $\begin{array}{c}\text { Nilai TSS Citra } \\
\text { SPOT6 mg/L }\end{array}$ & $\begin{array}{c}\text { Nilai TSS } \\
\text { Lapangan mg/L }\end{array}$ \\
\hline Uji 01 & 17,109 & & \\
Uji 02 & 24,066 & 12,701 & 19,8 \\
Uji 03 & 20,729 & 26,121 & 23,4 \\
Uji 04 & 24,737 & 22,123 & 19 \\
Uji 05 & 44,366 & 50,701 & 26,3 \\
\hline \hline
\end{tabular}

Konsentrasi TSS dari hasil pengolahan citra Pleiades 1A dan SPOT6 dengan hasil ground truth perlu dilakukan uji korelasi. Hal ini dilakukan untuk mengetahui kesesuaian hubungan antara dua peubah yaitu hasil pengolahan citra dan data pengukuran lapangan, sehingga perlu dilakukan perhitungan korelasi. grafik hasil perhitungan korelasi citra Pleiades 1A dan lapangan dapat dilihat pada Gambar 5.

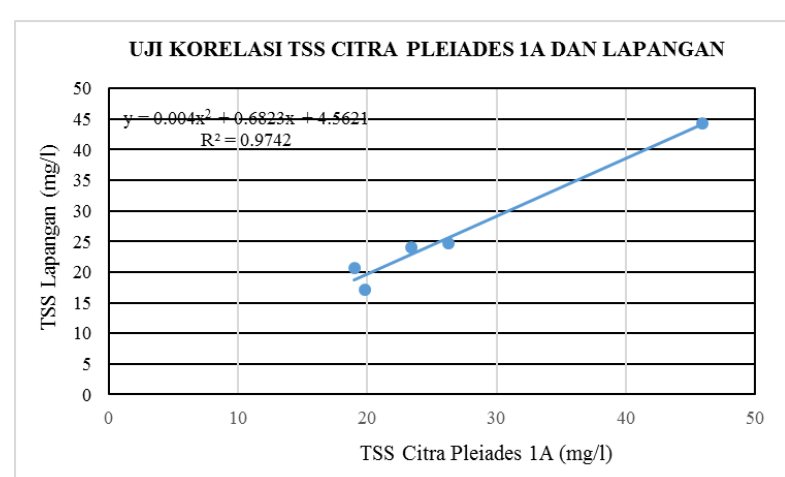

Gambar 5. Grafik Korelasi TSS Citra Pleiades 1A dan Lapangan

Sedangkan grafik hasil perhitungan korelasi antar citra satelit SPOT6 dan data lapangan dapat dilihat pada Gambar 6.

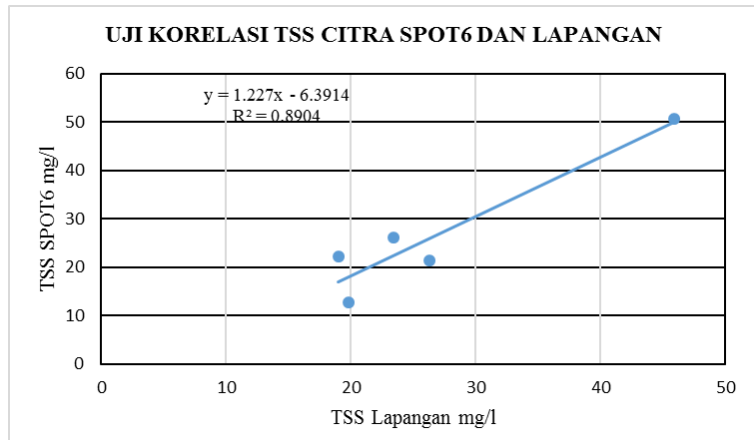

Gambar 6. Grafik Korelasi TSS Citra SPOT6 dan Lapangan

Hasil uji korelasi citra Pleiades 1A dan lapangan didapatkan korelasi sebesar (R) 0,98 sedangkan uji korelasi citra SPOT6 dan lapagan didapatkan korelasi sebesar (R) 0,94 . Sehingga dapat dikatakan bahwa hubungan interpertasi koefisien korelasi tergolong sangat kuat [8]. Dari perhitungan diatas baik dari data citra satelit maupun data ground truth TSS memiliki konsentrasi yang rendah $(<100 \mathrm{mg} / \mathrm{L})[9]$. Sehingga dari hasil tersebut daerah perairan laut Kecamatan Jenu tergolong bersih.

Hal tersebut menunjukkan bahwa konsentrasi TSS tidak memiliki pengaruh yang besar terhadap perubahan garis pantai khususnya di perairan laut Kecamatan Jenu. Karena peneliti tidak melakukan pengamatan pasang surut, sehingga untuk garis pantai menggunakan interpretasi citra Pleiades $1 \mathrm{~A}(09.54)$ [5].

\section{Uji Korelasi TSS Citra dan Foto Udara}

Pada penelitian yang telah dilakukan korelasi antara nilai TSS Citra dan Foto Udara, ditunjukkan pada Tabel 10.

$$
\text { Tabel } 10 .
$$

Perbandingan Nilai Konsentrasi TSS Citra Pleiades 1A, SPOT6 dan Foto

\begin{tabular}{cccc}
\multicolumn{4}{c}{ Udara } \\
\hline \hline $\begin{array}{c}\text { Point } \\
\text { ID }\end{array}$ & $\begin{array}{c}\text { Nilai TSS Citra } \\
\text { Pleiades 1A mg/L }\end{array}$ & $\begin{array}{c}\text { Nilai TSS Citra } \\
\text { SPOT6 mg/L }\end{array}$ & $\begin{array}{c}\text { Nilai TSS } \\
\text { Foto Udara } \\
\mathrm{mg} / \mathrm{L}\end{array}$ \\
\hline Uji 01 & 17,109 & 12,701 & 18,701 \\
Uji 02 & 24,066 & 26,121 & 18,701 \\
Uji 03 & 20,729 & 22,123 & 12,719 \\
Uji 04 & 24,737 & 21,3 & 18,701 \\
Uji 05 & 44,366 & 50,701 & 18,701 \\
\hline \hline
\end{tabular}

Uji korelasi dilakukan guna mengetahui hubungan antara kedua data. grafik hasil perhitungan korelasi citra Pleiades 1A dan foto udara dapat dilihat pada Gambar 7.

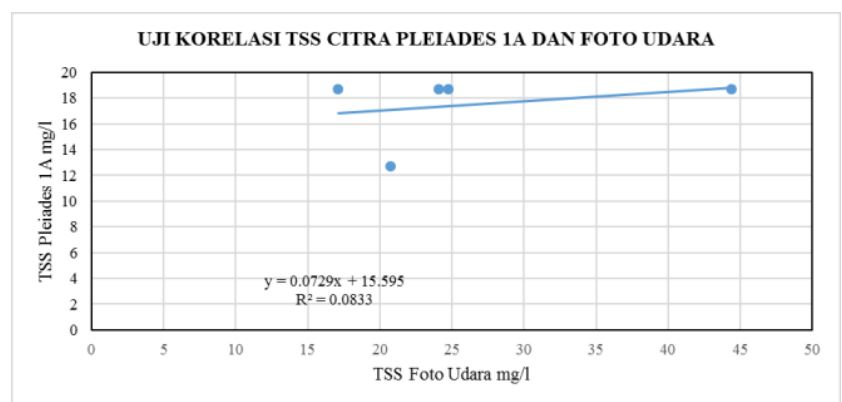

Gambar 7. Grafik Korelasi TSS Citra Pleiades 1A dan Foto Udara

Dari grafik diatas diketahui bahwa nilai korelasi (R) 0,28 sehingga dapat dikatan bahwa korelasi antara TSS pengolahn citra Pleiades 1A dan foto udara tergolong rendah [8]. Sedangkan uji korelasi TSS citra SPOT6 dan foto udara dapa dilihat pada Gambar 8.

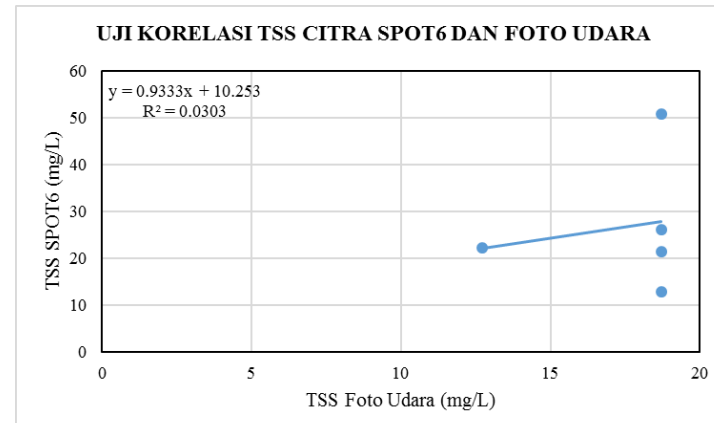

Gambar 8. Grafik Korelasi TSS Citra SPOT6 dan Foto Udara 
Hasil uji korelasi citra SPOT6 dan foto udara didapatkan korelasi sebesar (R) 0,17. Sehingga dapat dikatakan hubungan koefisien korelasi antara SPOT6 dan foto udara memiliki hubungan korelasi yang sangat rendah [8].

\section{J. Peta Garis Kecamatan Jenu Tuban}

Hasil peta dasar RDTR wilayah pesisir Kecamatan Jenu Tuban dapat dilihat pada Gambar 9.

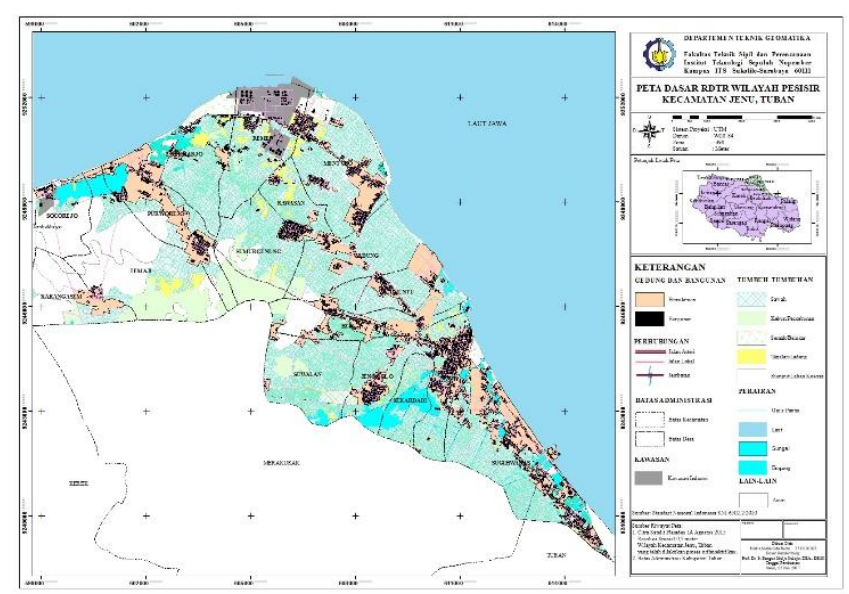

Gambar 9. Peta Dasar RDTR Wilayah Pesisir Kecamatan Jenu, Tuban

Klasifikasi yang digunakan berdasarkan aturan SNI RBI, 2010[10]. Namun disesuaikan dengan kondisi lokasi studi kasus yaitu Kecamatan Jenu, Tuban.

\section{KESIMPULAN DAN SARAN}

Berdasarkan hasil analisis yang telah dilakukan pada pembahasan sebelumnya, maka dapat diperoleh kesimpulan dari penelitian ini sebagai berikut:

1. Pada proses orthorektifikasi menggunakan 11 koordinat titik Kontrol Tanah (GCP), yang mana didapatkan nilai RMSE citra Pleiades 1A 0,108 meter dan citra SPOT6 0,642 meter.

2. Berdasarkan pada Peraturan Kepala BIG Nomor 15 tahun 2014 [3], maka dilakukan proses perhitungan uji ketelitian horizontal menggunakan 12 koordinat titik ICP. Dengan ketelitian horizontal citra Tegak Pleiades 1A $0,3 \mathrm{~m}$, sehingga citra Tegak Pleiades 1A hasil orthorektifikasi dikatakan memenuhi syarat pembuatan peta dasar RDTR skala 1: 2.500 kelas 1. Sedangkan citra SPOT6 memiliki ketelitian horizontal $1,8 \mathrm{~m}$, dan memenuhi syarat untuk pembuatan peta dasar RDTR skala 1: 5.000 kelas 3. Hasil tersebut akan diekomendasikan dalam pembuatan peta dasar RDTR Wilayah Pesisir skala 1:5000 untuk citra Tegak Pleiades 1A dan 1:10.000 citra Tegak SPOT6.

3. Tingkat konsentrasi TSS di perairan laut Kecamatan Jenu terbilang rendah yaitu $<100 \mathrm{mg} / \mathrm{L}$ [9]. Sehingga konsetrasi TSS yang rendah tersebut tidak memiliki pengaruh besar terhadap perubahan garis pantai di Kecamatan Jenu. Dalam penelitian penentuan garis pantai yaitu menggunakan interpretasi citra Pleiades 1A (09.54) yang mengacu pada Modul Validasi Peta Rencana Tata Ruang [5]. Adapun korelasi antara data ground truth dan data hasil pengolahan citra Pleiades $1 \mathrm{~A}$ dan SPOT6 yaitu tergolong sangat kuat sedangkan hubungan koefisien korelasi data citra Pleiades 1A dan SPOT6 dan foto udara tergolong rendah dan sangat rendah [8].
Adapun saran yang diberikan dari pelaksanaan penelitian ini untuk penelitian selanjutnya yaitu untuk pengambilan data lapangan menggunakan foto udara sebaiknya menggunakan foto udara yang memiliki sensor Near Infra Red (NIR) sehingga jika diolah menggunakan algritma TSS menghasilkan korelasi yang kuat antara TSS citra dan TSS hasil pengolahan foto udara.

\section{DAFTAR PUSTAKA}

[1] H. dkk Sihombing, W, "Kajian Kenaikan Muka Air Laut di Kawasan Pesisir Kabupaten Tuban," 2012.

[2] A. Utami, V. H dan Pamungkas, "Identifikasi Kawasan Rentan Terhadap Abrasi di Pesisir Kabupaten Tuban," J. Tek. POMITS, vol. 2, pp. 2337-3539, 2013.

[3] B. I. Geospasial, Peraturan Kepala Badan Informasi Geospasial Nomor 15 Tahun 2014 Tentang Pedoman Teknis Ketelitian Peta Dasar. Cibinong, 2014.

[4] A. Julzarika, "Perbandingan Teknik Orthorektifikasi Citra Satelit SPOT5 Wilayah Semarang dengan Metode Digital Mono Plotting (DMP) dan Metode Rational Polynomial Coefficients (RPCs)," Peneliti Bid. Bangfatja, Pusbangja, 2009.

[5] B. I. Goespasila, Modul Validasi Peta Rencana Tata Ruang. Bogor: Sekertariat BIG, 2016.

[6] H. Z. Abidin, Penentuan Posisi dengan GPS dan Aplikasinya (edisi 3). Jakarta: PT. Pradnya Paramita, 2007.

[7] N. dkk Laili, "Development of Water Quality Parameter Retrieval Algoritmhs For Estimating Total Suspended Solids and Chlorophyl-A Concentration Using Landsat-8 Imagery at Poteran Island Water," 2015.

[8] Sugiono, "Hipotesis Statistik," 2007. 